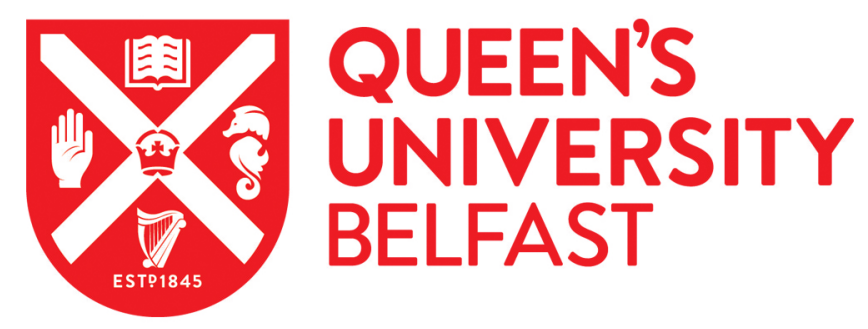

\title{
Implantable Cardioverter Defibrillator (ICD) Functionality: Patient and Family Information for advanced decision-making
}

Hill, L., Mcllfatrick, S., Taylor, B., Dixon, L., \& Fitzsimons, D. (2019). Implantable Cardioverter Defibrillator (ICD) Functionality: Patient and Family Information for advanced decision-making. BMJ Supportive and Palliative Care, Online, [e001835]. https://doi.org/10.1136/bmjspcare-2019-001835

\section{Published in:}

BMJ Supportive and Palliative Care

\section{Document Version:}

Peer reviewed version

Queen's University Belfast - Research Portal:

Link to publication record in Queen's University Belfast Research Portal

\section{Publisher rights}

(c) Author(s) (or their employer(s)) 2019. This work is made available online in accordance with the publisher's policies. Please refer to any applicable terms of use of the publisher.

\section{General rights}

Copyright for the publications made accessible via the Queen's University Belfast Research Portal is retained by the author(s) and / or other copyright owners and it is a condition of accessing these publications that users recognise and abide by the legal requirements associated with these rights.

Take down policy

The Research Portal is Queen's institutional repository that provides access to Queen's research output. Every effort has been made to ensure that content in the Research Portal does not infringe any person's rights, or applicable UK laws. If you discover content in the Research Portal that you believe breaches copyright or violates any law, please contact openaccess@qub.ac.uk. 
"Implantable Cardioverter Defibrillator (ICD) Functionality: Patient and Family Information for advanced decision-making".

\section{Details of corresponding author:}

Dr. Loreena M. Hill (PhD),

School of Nursing and Midwifery,

Queen's University,

Room 05:322 MBC building,

97 Lisburn Road,

Belfast.

BT9 7BL

\section{I.hill@qub.ac.uk}

Telephone: 02890975756

\section{Co-Authors Affiliations:}

Prof. Sonja Mcllfatrick: Professor of Nursing and Palliative Care, School of Nursing, Institute of Nursing and Health Research, Ulster University Jordanstown, Room 12J08, Shore Road, Newtownabbey, Co. Antrim, Northern Ireland BT37 0QB

Prof. Brian Taylor: Professor of Social Work, School of Applied Social and Policy Sc, Institute of Research in Social Sciences, Ulster University Magee, Room 21D11, Londonderry, Northern Ireland, BT48 7JL

Dr. Lana Dixon: Consultant Cardiologist, Royal Group of Hospitals, Belfast Health and Social Care Trust, Grosvenor Road, Belfast, Northern Ireland, BT12 6BA

Prof. Donna Fitzsimons: Head of School, School of Nursing and Midwifery, Queen's University, MBC Building, 97 Lisburn Road, Belfast, Northern Ireland BT9 7BL

Key Words: Chronic conditions, Clinical decisions, Quality of life, Supportive care

Word Count: 3558 


\section{Abstract}

As the number of implantable cardioverter defibrillators implanted continues to rise, there is a growing challenge to ensure patients and family members are adequately equipped for involvement in future end-of-life decisions concerning their device.

Objective: To explore patients', family members' and professionals' attitudes and understanding towards discussing implantable cardioverter defibrillator deactivation.

Methods: Case study approach using qualitative interviews and framework analysis.

A total of 29 qualitative interviews were undertaken, involving patients with a device, family members and healthcare professionals. Interviews were audio-recorded, transcribed verbatim and analysed using framework analysis. Data were triangulated with information obtained from the patients' medical records $(n=10)$.

Results: Three main themes:

- Professionals were reluctant to engage in conversations concerning deactivation, particularly prior to implantation, believing this was in the patient's best interest.

- Patients and family members had limited understanding of the implanted device and its functions. It was frequently perceived as 'life-saving' with any negativity of the shock experience seen as acceptable.

- All patients wanted the opportunity to discuss deactivation when death was imminent, but were indecisive whether family members should be involved. Similarly, some patients felt the decision to deactivate rested solely with the medical profession while others felt it should be a joint decision between patient, family and clinical team.

Conclusions: Patients and family members require improved communication and information concerning their future treatment plan and functionality of an implantable cardioverter defibrillator. A proactive approach to discuss deactivation would enable shared clinical decision-making in the advanced stages of illness.

\section{Introduction}

Given the rising rates of ICD implantation world-wide, the clinical concern of device deactivation is occurring more frequently within clinical practice as there is growing evidence that practice is sub-optimal $(1,2)$. An essential component of effective healthcare provision is patient education, empowering patients and their families to maintain, monitor and manage self-care of their underlying illness (3). For patients with an Implantable Cardioverter Defibrillator (ICD) and their families, understanding the functionality of their device will inform decisions concerning its management particularly in the advanced stages of illness $(4,5)$. Clinical guidelines and expert position papers (6-9) recommend healthcare professionals discuss deactivation of the device, however empirical studies report many are reluctant to 
engage in these conversations $(1,10,11)$. Possible explanations include the maintenance of patients' hope (11), decline in patient's cognitive ability (12) or simply a lack of time (11). Exploring the clinical concerns from patients', family members' and healthcare professionals' perspectives may facilitate development of strategies to improve current practice.

Previous studies that used qualitative (13), quantitative (14) or mixed method (15) designs concluded most patients with an ICD are unaware of the potential for deactivation and the implications of an active device on their quality of life at the end-of-life. Indeed, a systematic review of eighteen studies ( $n=5810$ patients) found diverse preferences amongst patients and their willingness to discuss ICD deactivation, ranging from only $12 \%$ of patients $(n=9)$ in an Irish study to $79 \%$ of patients $(n=195)$ in a Dutch cohort (16). Person-centred care embraces the patient as a central partner (17) with respect to the nuances each patient, clinical team and circumstances brings to the joint planning of care. This article builds on previous international work contributed by this research team $(1,16,18)$ and others $(10,19)$, to provide an in-depth understanding of the real-life challenges to discuss deactivation.

Objective: To explore patients', family members' and healthcare professionals' perspectives and attitudes towards discussing ICD deactivation.

\section{Methods}

This study conformed to the principles outlined in the Declaration of Helsinki (20) and was approved by the local Office for Research Ethics (Rec Reference: 13/NI/0008, January 2013). Case study research is "an empirical in-depth inquiry of a contemporary phenomenon within a real world context, using specific techniques of data collection and analysis" (Yin (21), page 16). It has been frequently used to explore complex phenomena from a range of different, complementary perspectives (22), with the term 'case' in this study referring to a patient, their family member and two members of the patient's clinical team (Cardiologist and Heart Failure Nurse). Researcher, an experienced female cardiology nurse (LH), collected data over a sixmonth period (August 2013 to January 2014) from qualitative interviews with patients $(n=10)$, family members $(n=10)$ and healthcare professionals involved in each case $(n=9)$. Discussions were digitally recorded, anonymised and transcribed verbatim before Framework Analysis (23). This form of data analysis has a straightforward and systematic process, whereby the transcripts were repeatedly read, examined and interpreted by two independent researchers to identify key topics. Initially illustrated as data extracts, key topics were discussed, refined and developed into more abstract themes, ensuring transparency in results with conclusions that can be related back to original data. Demographic and clinical information on age, gender, New York Heart Association (NYHA), co-morbidities, duration of ICD implantation and number 
of shocks experienced were collected from each patient's medical case note $(n=10)$. The COREQ qualitative research reporting guidelines were applied to ensure precision and reliability of findings (24).

Sample: A purposive sample of patients with an ICD who attended a tertiary cardiology outpatient department and met the inclusion criteria (Table 1), were invited to participate by their Consultant Cardiologist. The exact number of cases required was not specified at the onset, with data collection continuing until no new themes were being generated (25). Maximum variation approach to sampling incorporated a broad range of patient variables, for example age, gender and NYHA class. If the patient was willing to participate, he/she was asked to nominate a family member. Only if both individuals were willing, were their contact details relayed to the researcher, who then met to discuss and provide detailed information on the study. Written informed consent from both parties was obtained after one week 'cooling off' period, prior to conduction of the interviews.

\section{Refer to Table 1 (INSERT)}

Data collection: Each patient and family member were allocated an individual identifier number. It was preferred that participants were interviewed separately for up to 60 minutes within the patient's home. An interview guide (Refer Appendix 1) developed in line with Robson (2001)(26), ensured a 'laddered style' questioning approach, whereby initial questions were broad and less specific, allowing progress to more emotional and deeper issues in line with patients' level of disclosure (27). A distress protocol and continual vigilance by the researcher ensured emotional upset was minimised. Written informed consent was obtained from at least two members of each patient's clinical team to participate in the qualitative study. At a time and in a private setting convenient for the healthcare professionals, they reflected and openly discussed the issue of deactivation in relation to the specific case, with researcher acting as facilitator and moderator (28). The conjoint interviews with the healthcare professionals lasted 30-60 minutes. All interviews were audio-recorded and transcribed verbatim by an experienced research secretary under a strict confidentiality agreement. Participants were provided the opportunity to review and comment on their transcribed interview. Transcriptions, or anonymised 'thick descriptive' data were participant-centred and contextualised using the demographic and clinical information from patients' medical notes.

Data analysis: An inductive approach of Framework analysis (23) enabled inclusion of both a priori and emergent themes. A priori themes were derived from a systemic literature review completed by the researchers (16), the interview guide and study objectives. Interview $(n=29)$ transcripts were analysed manually by three researchers (LH, SMI, DF) before emerging 
themes were inserted into the framework matrix. The process required familiarisation with the interview, identification of a thematic framework, indexing, charting, mapping and interpretation (27). Its systematic, repetitive and reflective nature was enhanced by discussion and verification of meanings and explanations between the research team, clinical experts and healthcare professionals involved in the study. "Across" case analysis enabled a collective understanding of ICD deactivation from all ten cases.

Results: A total of sixteen patients were initially approached; four patients were unwilling to participate due to work and personal circumstances. One patient died prior to obtaining consent and one patient withdrew due to their condition deteriorating prior to interview. A total of ten patients and ten family members were included in the study. Most of the family members were either a spouse or sibling. Data saturation was reached prior to consent of the $10^{\text {th }}$ conjoint professional interview.

Characteristics of the patient sample within the case studies can be viewed in Table 2 INSERT Table 2

- Patients ranged from 49 years to 82 years of age, majority male $(n=7)$ and lived with a spouse $(n=7)$.

No changes or withdrawal of data were requested by participants after review of their transcript. Following the systematic and rigorous process of Framework analysis, three themes were identified which were 'explicit and grounded' in the original data. These include;

- Limited information provided

- Inaccurate understanding of the functionality of the ICD

- Patients' choices and decisions at the end-of-life compromised

The three themes, eleven sub-themes and some example quotes (in italics) are illustrated in Table 3 (INSERT)

\section{Limited information provided}

International guidelines recommend that deactivation is discussed prior to implantation, however professionals believed it could "make it difficult for patients to go through the consent process" (clinician 7). Some professionals perceived discussing deactivation equated to the "next step, preparing for death" and patients were not at that stage (clinician 2). Similarly, many professionals rationalised their reluctance to discuss due to the possibility that patients may have recently survived a life-threatening event and would "have enough to deal with 
mentally" (Clinician 7). Patient 6, an 82-year-old teacher noted that "you take in about half of what you are told", while the family member of patient 5 noted that discussing deactivation would have been too "difficult and probably better discussed at a later stage".

Patients reported written information was "rudimentary" (Patient 7), resorting to sourcing details on the internet. The majority were uncertain how deactivation would be accomplished and its immediate consequences. Patient 2, a 49-year-old female patient described it like a ventilator, whereby deactivation was "just turning my machine off".

A number of patients stated they were aware that aspects of their illness and future management had not been disclosed, and they questioned the rationale for this. Patient 3 , a 60-year-old male noted

"Maybe as a patient l'm not supposed to know? Maybe the medical profession think patients don't have the intelligence to accept a wee bit more knowledge?".

Despite this insight, many patients were uncertain of the quantity and depth of information that they would be comfortable with receiving. The following comment by patient 8 depicts this opinion- "I leave it in the hands of the doctors because they have got me this far". Both patients and professionals placed value on a supportive professional: patient relationship, with patients placing "trust in what we were told" (Patient 1) and professionals desiring an understanding of patients' information and emotional needs before embarking on this sensitive topic.

Majority of the professionals believed it was appropriate to wait until the patient broached the subject of deactivation, indicating that "no time is really the right time" (Clinician 6). They considered their actions in terms of limiting information, to be in the patient's best interests as

"Each patient has to be managed as an individual, how much information they want and what route they want to take the discussion" (Clinician 8).

The clinical team of Patient 9 noted her avoidance of discussing end-of-life issues, describing it as - "a defence mechanism, we don't talk about it we don't think about it and then it is not there" (Clinician 9). Their actions were supported by her husband who believed such conversations would "kill her, it would break her heart" (Family member 9). A further factor mentioned by Clinician 2 which would affect the exchange of information concerning deactivation was that of age. It was noted that healthcare professionals' may be more reluctant to discuss deactivation with the younger patient. "If she didn't ask it would be more difficult to raise it with her... she is quite young" (Clinician 2). Triangulated data from all sources confirms 
that generally deactivation was not discussed prior to device implantation. Professionals believed a more opportune time would arise during the course for device implantation.

Inadequate understanding of the functionality of the ICD

Patients described their ICD, as "lifesaving", making them feel "protected" with a "great insurance if you need it". The sister of patient 8 said, "I think he feels that he can't die when it (ICD) is there because that will start the heart again". Patients coped daily with a range of complex and unpredictable heart failure symptoms, as well as being emotionally unsure about their prognosis and the possibility of a shock. This lack of information and uncertainty left people feeling "not in control of your own destiny" as described by patient 3. Lived experiences, provided patients and family members the opportunity to question and learn about their ICD. Patient 3, who had experienced multiple shocks regarded his ICD as "a manmade device to bring you back to sinus rhythm", compared to patient 6 who had experienced no shocks and believed "the ICD is guaranteed to save your life". Patient 10, an 80 -year-old gentleman made the decision to deactivate his device due to an increased awareness of declining health and not wanting to be a burden on his family.

Seven patients who received a shock from their ICD expressed how they did not fully appreciate the functioning of the device until it first discharged. Patient 2 described in graphical detail what it was like- "It was like as if you were in a bomb - and you survived it". Furthermore, neither patients nor family members could comprehend that a shock could be inappropriate. Healthcare professionals supported the positive aspect of a shock; "it was keeping him alive and he wanted to stay alive" (Nurse 3) or "the device had done exactly what it was supposed to do" (Clinician 8). Only when patients were diagnosed as in the advanced stages of illness, did professionals question the role of the ICD. For example:

"if his condition deteriorates and we think he is reaching that stage, yes we will discuss it with him" (Clinician 5).

Patients within this study did not understand the functions of their device and held an optimistic belief into its ability. Despite the pain and distress a shock caused, most expressed reluctance to deactivate the device. However, the extent to which this is an informed decision is uncertain.

\section{Patients' choice and decisions at the end-of-life compromised}

Patients lacked insight into their illness, prognosis and the potential impact of the ICD on their death. Clinical indicators that inhibited professionals from initiating the discussion included; the patient's management was "going down the treatment route" (Clinician 3), the health problem was a "retrievable situation" (Clinician 9) or the patient "has been through a life- 
threatening illness" (Clinician 6). The discussion and decision to deactivate were intrinsically linked, with one automatically preceeding the other. Consequently, patients felt the decision to deactivate their device should be made in the last few minutes of life. This was illustrated by two patients who felt the discussion should take place when he was a "no hope corpse" (Patient 7) and when the "cardiologist was on his knees beside me and said I was gone" (Patient 3). Patient 2 felt she "did not need to know about deactivation at the minute, there probably will be a time when I need to know".

The majority of patients wanted to be involved in the decision to deactivate their device, however agreed that a medical professional should make the final judgement. Patient 3 adamantly believed

"no-one has the right to make the decision for you that isn't medically trained", "I wouldn't override a medical decision because I am totally unqualified"

All ten patients withheld prognostic information and feelings from family members and vice versa. There was a conspiracy of silence between patients and family members as highlighted in the case of patient 10, as he described how he would "just slide over the wee things that you don't want them to know". Some carers were aware that they were not fully informed about their loved one's condition or device. For example, "hiding things", "putting on an act" in front of their children and how she "didn't feel aware of everything that was going on" were thoughts described by the carer of Patient 3. Furthermore, a number of family members believed discussing end of life issues would "knock the stuffing out of him" (Family member 5) or "horrible for her, no way would I share any of that" (Family member 6). Most patients however wanted to discuss issues with their clinical team, yet hesitated to disclose conversations with family members. One patient noted how family members can be "overwhelming, they would be far better staying away for a day and letting you breath" (Patient 1). The impact this had on family dynamics could be perceived by the clinical team, as one professional put it; he was "putting on a brave face in front of her" and "was trying to protect her from how sick he was" (Clinician 3)

Involvement of family members was also valued, as Patient 2 believed the decision should be "made with them, my family and hopefully partner and me". Professionals supported this view, as illustrated by Clinician 7:

"ICD deactivation is something that you need to have the family on board with", to help when "the patient would no longer be around to pick up the pieces and face the fall-out". 
This was particularly evident when discussing the issue of capacity as the majority of professionals agreed that "if the patient was conscious the decision should be with the patient" (Clinician 2). However, when the patient was incapable or "unconscious", professionals, carers and patients agreed that the decision then resides with the doctor. Professionals often relied on clinical indicators to determine discussing deactivation.

\section{Discussion}

The ten case studies provided an in-depth and holistic understanding of the information provided to patients and their family members by healthcare professionals concerning ICD deactivation. Discussing deactivation was considered important by healthcare professionals, however doing so was often determined by their experiential knowledge of the patient rather than evidence-based information. Results highlight three points warranting discussion.

\section{Tailored information or event-driven information?}

Expert guidelines and empirical studies stipulate the importance of healthcare professionals discussing ICD deactivation at certain time points (6-9). This is supported by expert patients involved in guideline development, as well as research studies $(29,30)$. However, a more individualised patient-centred approach to the delivery of information and discussion of deactivation is warranted.

Patients in this study valued information and appreciated why deactivation should be discussed before ICD implantation. There appeared to be a 'conspiracy of silence' between the professional, patient and family members, which could potentially jeopardise shared decision-making. A Czech Republic survey of 109 patients reported eight patients $(7 \%)$ had discussed deactivation prior to implantation, 44 patients, (40\%) would have liked more information and 19 patients (22\%) who received their device for primary prevention refused further information (31). Furthermore, an international factorial survey found the majority of experienced cardiology nurses believed deactivation should be discussed prior to implantation, while most medical professionals believed that the subject was best discussed at the end-of-life (18). Discussing deactivation at this late stage in the patient's life may be "too little; too late" (1), leaving limited time for patients and family members to prepare.

Indeed poor future planning can result in inadequate provision and coordination of services to address individual, changing and multifaceted care needs (32), for example an oncology study found patients who completed an advance directive were less depressed $(p=0.030)$ and more satisfied with their end-of-life care (33).

An alternative strategy could be tailored information provided sensitively by a professional known to the patient and family at opportune times through-out device implantation. A 
questionnaire has been successfully implemented as such an assessment and educational tool (34). There is need for more research on the informational needs and its optimal format for patients and their family.

Knowledge accrued from the 'lived experience' with an ICD

For many patients and their family members, knowledge was derived only from experience. With reference to a discharge from their ICD, patients who had experienced a shock were more decisive in their attitude towards deactivation. Our results correlate with findings from a Swedish study (30) who reported patients who had experienced a shock were more likely to have discussed prognosis and deactivation with their physician $(p<0.001)$ as well as their family $(p<0.001)$. Furthermore patients who have experienced a shock, generator replacement or had an end-of-life discussion with their physician, were more knowledgeable about end-oflife issues (5).

Some patients sought additional information to that provided by the professionals through accessing internet sources or patient support groups. One explanation could be the nature of the information as healthcare professionals often preferred to discuss clinical rather than psychosocial issues (35). This lack of person-centred information and support has a bearing on the experiences of family members (36), emphasising the need for professionals to improve education provided to both patients and their family members.

\section{Multidisciplinary team approach to optimal management}

In terms of the decision to deactivate the device, there was a consensus view that a medical professional's decision would be final. Similar results were noted both by patients (37) and healthcare professionals (38) internationally.

An American study emphasised the important contribution nurses could make to improve practice (13). Many specialist nurses believe they have the necessary knowledge and skills, however their experience and involvement in deactivation appears limited $(1,13,18)$. A survey of Swedish heart failure nurses (39) found several barriers explaining their reluctance, for example heart failure's unpredictable disease trajectory and the opinion patients with advanced heart failure were not end-of-life. Cardiac Physiologists play key role in deactivation, and may provide a valuable contribution to the discussion and decision process (18). Results from this study supports published evidence for a multi-professional approach to the management of all patients at the end-of-life (40) as well as re-clarify the evolving role of the specialist heart failure nurse. 
As with any study, a number of limitations require consideration. Sample size was in keeping with the qualitative design of the study, however the setting of data collection was cardiology outpatient departments within a single tertiary healthcare trust potentially limiting generalisability of results. Reluctance by professionals to discuss deactivation is a global concern $(10,18,19)$ and not unique to any geographical location.

\section{Conclusion}

Despite recently published clinical guidelines, the decision to embark on a discussion concerning ICD deactivation was idiosyncratic to the patient, family member and professional involved. Missed educational opportunities may account for why most patients and their family members held unrealistic perceptions of the ICD's functionalities, considering deactivation only from a hypothetical perspective. The provision of information and an empathetic discussion about deactivation early in the disease trajectory would provide an opportunity to be involved in advanced decisions, thereby taking control on whether or not to deactivate their ICD.

\section{Conflict of Interest}

None declared

\section{Funding}

The first author was supported by the Health and Social Care R\&D Division of the Public Health Agency for Northern Ireland through a doctoral training fellowship. The first author had attended one week course on Qualitative research methods.

\section{References}

(1) Hill L, Mcllfatrick S, Taylor BJ, Dixon L, Cole BR, Moser DK, et al. Implantable cardioverter defibrillator (ICD) deactivation discussions: Reality versus recommendations. European Journal of Cardiovascular Nursing 2015.

(2) Westerdahl AK, Sjoblom J, Mattiasson A, Rosenqvist M, Frykman V. Implantable Cardioverter-Defibrillator Therapy before death high risk for painful shocks at the end of life. Circulation 2014;129:422-429.

(3) Riegel B, Jaarsma T, Stromberg A. A middle-range theory of self-care of chronic illness . ANS Adv Nurs Sci 2012;35(3):194-204.

(4) Lee MC, Sulmasy DP, Gallo J, Kub J, Hughes M, Russell. S., et al. Decision-making of patients with implantable cardioverter-defibrillators at end-of-life. family members experience. American Journal of Hospice and Palliative Medicine 2017;34(6). 
(5) Stromberg A, Fluur C, Miller J, Chung M, Moser DK, Thylen I. ICD Recipients' understanding of ethical issues, ICD function, and practical consequences of withdrawing the ICD in the End-of-Life. PACE 2014;00:1-9.

(6) Padeletti L, Omar DO, Boncinelli L, Brachman J, Camm JA, Daubert JC, et al. EHRA expert consensus statement on the management of cardiovascular implantable electronic devices in patients nearing end of life or requesting withdrawal of therapy. . Europace 2010;12:1480-1489.

(7) Lampert R, Hayes DL, Annas GJ, Farley MA, Goldstein NE, Hamilton RM, et al. HRS consensus statement on the management of cardiovascular implantable electronic devices (CIEDs) in patients nearing end of life or requesting withdrawal of therapy. . Heart Rhythm 2010;7:1008-1026.

(8) Ponikowski P, Voors AA, Anker SD, Bueno H, Cleland JGH, Coats AJS, et al. 2016 ESC guidelines for the diagnosis and treatment of acute and chronic heart failure. The task force for the diagnosis and treatment of acute and chronic heart failure of the European Society of Cardiology. European Heart Journal 2016.

(9) Jaarsma T, Beattie JM, Ryder M, Rutten FH, McDonagh T, Mohacsi P, et al. Palliative care in Heart Failure: a position statement from the palliative care workshop of the Heart Failure Association of the European Society of Cardiology . European Journal of Heart Failure 2009;11:433-433-443.

(10) Marinski G, Van Erven L. Deactivation of implantable cardioverter-defibrillators at the end of life: results of the EHRA survey. Europace 2010;12:1176-1177.

(11) Dunlay SM, Foxen JL, Cole T, Feely MA, Loth AR, Strand JJ, et al. A survey of clinician attitude and self-reported practices regarding end-of-life care in heart failure. Palliative medicine 2015;29(3):260-267.

(12) Caldwell P, Arthur H, Demers C. Preferences of patients with heart failure for prognosis communication. . Canadian Journal of Cardiology 2007;23(10):791-796.

(13) Goldstein NE, Mehta D, Siddiqui S, Teitelbaum E, Zeidman J, Singson M, et al. "Thats like an act of suicide" patients attitudes toward deactivation of Implantable Defibrillators. J Gen Intern Med 2008;23(1):7-12.

(14) Yilmaz D, Schalij M, van Erven L. Patient awareness of Implantable cardioverter defibrillator-therapy deactivation when the end is near. Journal of the American College of Cardiology 2016;67(13):701.

(15) Raphael CE, Koa-Wing M, Stain N, Wright I, Francis DP, Kanagaratnam P. Implantable Cardioverter-Defibrillator Recipient attitudes towards device deactivation: How much do patients want to know? PACE 2011;34:1628.

(16) Hill L, Mcllfatrick S, Taylor B, Dixon L, Harbinson M, Fitzsimons D. Patients' perception of implantable cardioverter defibrillator deactivation at the end of life . Palliative medicine 2014.

(17) Ekman I, Wolf A, Olsson L, Taft C, Dudas K, Schaufelberger M, et al. Effects of personcentred care in patients with chronic heart failure: the PCC-HF study. European Heart Journal 2012;33:1112-1119. 
(18) Hill L, Mcllfatrick S, Taylor B, Jaarsma T, Moser D, Slater P, et al. Patient and Professional factors that impact the perceived likelihood and confidence of healthcare professionals to discuss Implantable Cardioverter Defibrillator deactivation in advanced heart failure. Results from an international factorial survey. Journal of Cardiovascular Nursing 2018.

(19) Fluur C, Bolse K, Stromberg A, Thylen I. Spouses' reflections on Implantable Cardioverter Defibrillator treatment with focus on the future and the end-of-life: a qualitative content analysis. Journal of Advanced Nursing 2014;70(8):1758-1769.

(20) World Medical Association. "Declaration of Helsinki: Ethical principles for medical research involving human subjects". 2013.

(21) Yin RK editor. Case study research: design and methods. 4th ed. ed. Los Angeles, Calif: Sage Publications; 2009.

(22) Fitzsimons D, Mullan D, Wilson JS, Conway B, Corcoran B, Dempster M, et al. The challenge of patients' unmet palliative care needs in the final stages of chronic illness.

Palliative medicine 2007;21:313-322.

(23) Ritchie J, Lewis J, McNaughton Nicholls C, Ormston R editors. Qualitative research practice: A guide for social science students and researchers . 2nd edition ed. London: Sage Publications; 2014.

(24) Tong A, Sainburg P, Craig J. Consolidated criteria for reporting qualitative research (COREQ): a 32 item checklist for interviews and focus groups. International Journal of Quality in Health Care 2007;19(6):349-357.

(25) Parahoo K editor. Nursing Research. Principles, process and issues. Basingstoke: Palgrave Macmillan; 1997.

(26) Robson C. Real World Research. A Resource for users of Social Research Methods in Applied settings. 3rd Edition ed. Chichester: Wiley; 2001.

(27) Ritchie J, Lewis J editors. Qualitative Research Practice: A guide for social science student and researchers. 1st Edition ed. London: Sage Publications; 2003.

(28) Tong A, Sainsbury P, Craig J. Consolidated criteria for reporting qualitative research (COREQ): a 32-item checklist for interviews and focus groups. International Journal for Quality in Health Care 2007 December 01;19(6):349-357.

(29) National Institute for Health and Care Excellence. Implantable Cardioverter Defibrillators and Cardiac Resynchronisation Therapy arrhythmias and heart failure (review of TA95 and TA120). 2014;NICE technology appraisal guidance 134.

(30) Thylen I, Moser DK, Chung ML, Miller J, Fluur C, Stromberg A. Are ICD recipients able to foresee if they want to withdraw therapy or deactivate defibrillator shocks? IJC Heart \& Vessels 2013:22-31.

(31) Herman D, Stros P, Curila K, Kebza V, Osmancik P. Deactivation of Implantable cardioverter-defibrillators: results of patient surveys . Europace 2013;15:963-969. 
(32) Low J, Pattenden J, Candy B, beattie JM, Jones L. Palliative care in advanced heart failure: An international review of the perspectives of recipients and health professionals on care provision. Journal of Cardiac Failure 2011;17231-252.

(33) Pautex S, Hermann FR, Zullian GB. Role of Advance Directives in palliative care units: A prospective study. Palliative medicine 2008;22(7).

(34) Thylen I, Wenemark M, Fluur C, Stromberg A, Bolse K, Arestedt K. Development and evaluation of the EOL-ICDQ as a means of experiences, attitudes and knowledge in end-oflife in patients living with an implantable cardioverter defibrillator. European Journal of Cardiovascular Nursing 2014;13(2):142-151.

(35) Tagney J, James JE, Albarran JW. Exploring the patient's experiences of learning to live with an implantable cardioverter defibrillator (ICD) from one UK centre: a qualitative study. European Journal of Cardiovascular Nursing 2003;2:195-203.

(36) Albarran JW, Tagney J, James J. Partners of ICD patients- An exploratory study of their experiences. European Journal of Cardiovascular Nursing 2004;3(3).

(37) Groarke J, Beirne A, Buckley U, O'Dwyer E, Sugrue D, Keelan T, et al. Deficiences in Patients' Comprehension of Implantable Cardioverter Defibrillator Therapy. PACE 2012;35:1097.

(38) Morrison LJ, Calvin AO, Nora H, Storey CP. Managing Cardiac devices near the End of Life: A survey of hospice and palliative care providers. American Journal of Hospice and Palliative Medicine 2010;27(8):545-551.

(39) Hjelmfors L, Stromberg A, Friedrichsen M, Martensson J, Jaarsma T. Communicating prognosis and end of life care to heart failure patients: A survey of heart failure nurses' perspectives. European Journal of Cardiovascular Nursing 2014;13(2):152-161.

(40) Boxer MM, Vinod SK, Shafiq J, Duggan KJ. Do multidisciplinary team meetings make a difference in the management of lung cancer? Cancer 2011;117(22):5112-5120. 
Table 1: Inclusion criteria for case studies

\begin{tabular}{|l|l|l|}
\hline \multicolumn{1}{|c|}{ Patients } & \multicolumn{1}{|c|}{ Family Members } & Healthcare Professionals \\
\hline $\begin{array}{l}\text { Diagnosis of Heart failure } \\
\text { and ICD implanted }\end{array}$ & Nominated by patient & $\begin{array}{l}\text { Involved in the clinical } \\
\text { management of the patient }\end{array}$ \\
\hline Over 18 years old & Over 18 years old & Willing to consent \\
\hline $\begin{array}{l}\text { Physically and mentally } \\
\text { capable of participation (as } \\
\text { judged by Cardiologist) }\end{array}$ & $\begin{array}{l}\text { Physically and mentally } \\
\text { capable of participation (as } \\
\text { judged by Researcher) }\end{array}$ & \\
\hline Willing and able to consent & Willing and able to consent & \\
\hline
\end{tabular}


Table 2: Characteristics of the patients within the case study

\begin{tabular}{|c|c|c|c|c|c|c|c|c|c|c|}
\hline Patient Number & Patient 1 & \begin{tabular}{|l|} 
Patient \\
2
\end{tabular} & Patient 3 & Patient 4 & Patient 5 & Patient 6 & Patient 7 & \begin{tabular}{|l|} 
Patient \\
8
\end{tabular} & Patient 9 & Patient 10 \\
\hline Age, years & 63 & 49 & 60 & 82 & 73 & 82 & 78 & 56 & 66 & 80 \\
\hline \multicolumn{11}{|l|}{ Clinical } \\
\hline $\begin{array}{l}\text { Ischaemic aetiology of } \\
\text { heart failure }\end{array}$ & Yes & No & Yes & Yes & Yes & Yes & Yes & Yes & Yes & Yes \\
\hline Co-morbidities & $\begin{array}{l}\text { Atrial } \\
\text { Fibrillation } \\
\text { Diabetes } \\
\text { Mellitus } \\
\text { Arthritis } \\
\text { Chronic Kidney } \\
\text { Disease }\end{array}$ & Asthma & $\begin{array}{l}\text { Slow } \\
\text { Ventricular } \\
\text { Tachycardia }\end{array}$ & $\begin{array}{l}\text { Chronic } \\
\text { Kidney } \\
\text { Disease }\end{array}$ & $\begin{array}{l}\text { Atrial } \\
\text { Fibrillation } \\
\\
\text { Chronic } \\
\text { Kidney } \\
\text { Disease }\end{array}$ & $\begin{array}{l}\text { Diabetes } \\
\text { Mellitus }\end{array}$ & $\begin{array}{l}\text { Abdominal } \\
\text { Aortic } \\
\text { Aneurysm } \\
\text { repair } \\
\text { Paroxysmal } \\
\text { Atrial } \\
\text { Fibrillation } \\
\text { Arthritis } \\
\end{array}$ & & $\begin{array}{l}\text { Chronic } \\
\text { Kidney } \\
\text { Disease } \\
\text { Obese } \\
\text { Arthritis }\end{array}$ & $\begin{array}{l}\text { Atrial } \\
\text { Fibrillation } \\
\text { Diabetes } \\
\text { Mellitus } \\
\text { Pulmonary } \\
\text { fibrosis }\end{array}$ \\
\hline $\begin{array}{l}\text { Duration of } \\
\text { implantation, years }\end{array}$ & 11 & 9 & 12 & 6 & 6 & 1 & 11 & 7 & 2 & 20 \\
\hline $\begin{array}{l}\text { Number of defibrillator } \\
\text { shocks received }\end{array}$ & 0 & 3 & 3 & $16-30$ & 2 & 0 & 0 & 29 & 10 & $>30$ \\
\hline
\end{tabular}


Table 3: Theme, Sub theme and examples of quotations

\begin{tabular}{|c|c|c|}
\hline Theme & Sub-Theme & Quotations \\
\hline $\begin{array}{l}\text { Limited } \\
\text { information by } \\
\text { professionals }\end{array}$ & $\begin{array}{l}\text { Reluctance to } \\
\text { discuss } \\
\text { deactivation } \\
\text { Patients' are } \\
\text { too ill to } \\
\text { understand } \\
\text { information } \\
\text { pre- } \\
\text { implantation } \\
\text { Imperative to } \\
\text { maintain hope }\end{array}$ & $\begin{array}{l}\text { "The new guidelines to discuss end-of-life } \\
\text { issues at the time of implant are not } \\
\text { something that I am going to adopt" } \\
\text { (Clinician 8). } \\
\text { "it is about prolonging life, stopping } \\
\text { death...deactivation means thinking of a } \\
\text { totally next step about preparing for death" } \\
\text { (Clinician 2) } \\
\text { "Defence mechanism; we don't talk about it } \\
\text { and then it is not there" (Clinician 9) }\end{array}$ \\
\hline $\begin{array}{l}\text { Inaccurate } \\
\text { understanding } \\
\text { of ICD } \\
\text { functionality }\end{array}$ & $\begin{array}{l}\text { ICD portrayed } \\
\text { as a lifesaver } \\
\text { Experience of } \\
\text { a shock }\end{array}$ & $\begin{array}{l}\text { "manmade device that is keeping me alive" } \\
\text { (patient 3) } \\
\text { "I know that I am safe because it will kick } \\
\text { me, it would not give a hard kick for nothing, } \\
\text { that is why it is there" (patient 9) } \\
\text { "I would hate to die prematurely over the } \\
\text { sake of a lot of shocks" (patient 3) }\end{array}$ \\
\hline $\begin{array}{l}\text { Choice and } \\
\text { decisions } \\
\text { compromised }\end{array}$ & $\begin{array}{l}\text { Who should } \\
\text { make the } \\
\text { decision }\end{array}$ & $\begin{array}{l}\text { "healthcare professionals should make the } \\
\text { decision and tell you" (patient 5) } \\
\text { "The decision will be made with them ones, } \\
\text { my family and hopefully partner and me" } \\
\text { (patient 2) } \\
\text { "I didn't feel aware of everything that was } \\
\text { going on" (family member 3). }\end{array}$ \\
\hline
\end{tabular}


Funding: Through a Doctoral Fellowship award by the Department of Health, Social Services and Public Safety, R\&D division, Northern Ireland.

Competing interests: There are no competing interests with the author

Exclusive license: I (Loreena Hill), the Submitting Author has the right to grant and does grant on behalf of all authors of the Work (as defined in the below author licence), an exclusive licence and/or a non-exclusive licence for contributions from authors who are: i) UK Crown employees; ii) where BMJ has agreed a CC BY licence shall apply, and/or iii) in accordance with the terms applicable for US Federal Government officers or employees acting as part of their official duties; on a worldwide, perpetual, irrevocable, royalty-free basis to BMJ Publishing Group Ltd ("BMJ") its licensees and where the relevant Journal is co-owned by BMJ to the coowners of the Journal, to publish the Work in BMJ Supportive and Palliative Care Journal and any other BMJ products and to exploit all rights, as set out in our licence [link]."

Ethics statement: This study conformed to the principles outlined in the Declaration of Helsinki and was approved by Office for Research Ethics Committee Northern Ireland (ORECNI) REC Reference: 13/NI/0008. Governance approval was granted by the Belfast Health and Social Care Trust: Trust R\&D Ref 12092DF-AS 